\title{
DIAGNOSIS OF SUBCUTANEOUS CYSTICERCOSIS IN SOFT TISSUE MASS OVER ANTERIOR ABDOMINAL WALL: A CASE REPORT AND REVIEW OF THE LITERATURE.
}

Pravin Pawane, Balamurugan M, Pillai R, Pradeep Kumar N. S.

Sri Lakshminarayana Institute of Medical Sciences, Pondicherry.

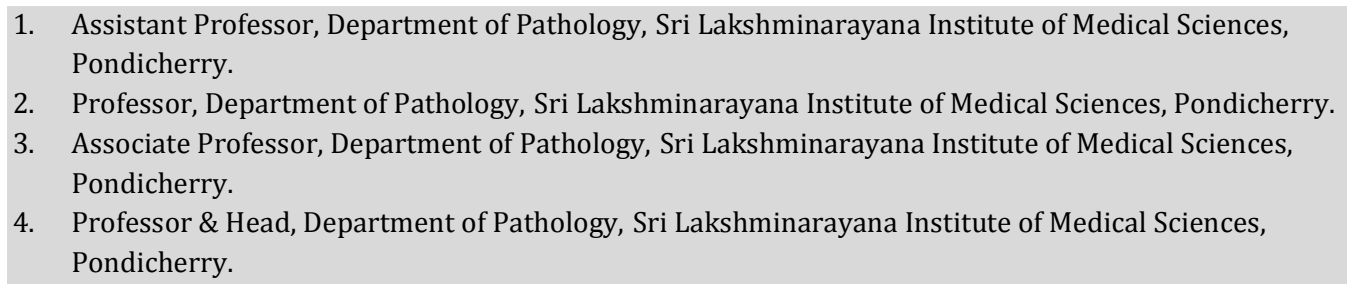

1. Assistant Professor, Department of Pathology, Sri Lakshminarayana Institute of Medical Sciences, Pondicherry.

2. Professor, Department of Pathology, Sri Lakshminarayana Institute of Medical Sciences, Pondicherry.

3. Associate Professor, Department of Pathology, Sri Lakshminarayana Institute of Medical Sciences, Pondicherry.

4. Professor \& Head, Department of Pathology, Sri Lakshminarayana Institute of Medical Sciences, Pondicherry.

\section{CORRESPONDING AUTHOR}

Dr. Pravin Pawane, MD Pathology,

No: 12, Block: 2, Sri Lakshminarayana

Institute of Medical Sciences Agaram Village,

Osudu, Pondicherry-605502 INDIA

E-mail: johnprav4470@gmail.com

Ph: 00918015352114.

ABSTRACT: BACKGROUND: Cysticercosis commonly presents as neural or intramuscular lesion. Rarely, it may present in soft tissues in the adult age group. CASE DETAILS: A 42-yearold male presented with pain and swelling over the right lateral abdominal wall. The pain was progressive towards sub-costal region. It was clinically diagnosed as Fibromatosis / Desmoid tumor. Abdominal ultra-sound revealed possibility of Desmoid / Dermoid / Infective cyst. Surgical excision was performed. The final diagnosis of Subcutaneous Cysticercosis was made based on the histopathological findings. CONCLUSION: Even though cysticercosis is common in brain and skeletal muscle, it is rare at subcutaneous location. Therefore the possibility of cysticercosis should be considered in the differential diagnosis of subcutaneous swelling in the adult age group.

KEY WORDS: subcutaneous cysticercosis, cysticercosis in soft tissue mass

INTRODUCTION: The adult Taenia solium tapeworms are found in the small intestine of humans, the definitive host, and the Cysticercus cellulosae, the larval forms of the tapeworm Taenia solium are found in the skeletal muscle of the intermediate host, the pig. To develop cysticercosis, a human has to replace the pig in the T. solium life cycle and the eggs must mature within the human small intestine as they would do in the pig's intestine. Entry of the eggs into the human small intestine may occur through autoinfection or by inhalation or ingestion of eggcontaminated food or water. Finally these cysticerci spread through the intestinal wall and are carried by the blood stream to muscles, brain and subcutaneous tissues, leading to clinical manifestations [1].

CASE REPORT: A 42-year-old male, known case of diabetis mellitus from Puducherry presented with swelling over the right lateral abdominal wall which had gradually increased in size over the previous year. 
On examination swelling of size $2 \times 1.8 \mathrm{cms}$ was present in the right flank associated with localized pain which was progressive towards sub-costal region and was clinically diagnosed as Fibromatosis / Desmoid tumor.

Investigations revealed hemoglobin of 13.5 gm\%. FNAC examination was in favor of costo-chondritis. Abdominal ultrasound revealed an irregular, heterogeneous, partly cystic mass measuring $1.8 \times 1.7 \mathrm{cms}$, deep to subcutaneous tissue and superficial to external oblique aponeurosis suggesting Desmoid / Dermoid / Infective cyst. Surgical excision was performed \& sample was sent for histopathology examination.

On gross examination, it was an elliptical tissue piece partly covered with skin measuring $1.8 \times 1.7 \times 1.5 \mathrm{cms}$. Cut section showed a tiny cyst surrounded by pale, fibrous tissue. Center of the cyst showed a curled, white structure. Microscopically, there was a cyst with a coiled parasite. The cyst was surrounded by dense fibrous wall and showed prominent investing cuticle with presence of single degenerating sucker, aggregated subcuticular cells, smooth mucle fibres inflammation, presence of calcospherules and fragments of wall. The final diagnosis of Subcutaneous Cysticercosis was made based on the histopathological findings.

DISCUSSION: Humans are the only definitive host and harbour the adult tapeworm. Humans can also act as intermediate hosts by ingestion of food contaminated with Taenia solium eggs. Airborne transmissions of Taenia solium eggs and autoinfection by regurgitation of proglottids into the stomach of patients with taeniasis have not yet been demonstrated as routes of infection. Therefore, cysticercosis in humans is almost always caused by cysticercosis cellulose and results due to infection with eggs of taenia solium.[2] Taenia solium infestation is rampant in many parts of the world, including Russia, China, India, Mexico, Philippines, Pakistan and Nepal.[3] Widespread dissemination of cysticerci throughout the human body was reported as early as 1912 by British Army medical officers stationed in India [4]. Priest, in 1926, described probably the first case of extensive somatic dissemination of C. cellulosae in a British soldier who had swelling of his muscles, epileptic seizures, mental dullness and widespread subcutaneous nodules [5].

CONCLUSION: Even though Cysticercosis is common in brain and skeletal muscle, it is rare at subcutaneous location. Therefore the possibility of Cysticercosis should be considered in the differential diagnosis of subcutaneous swelling in the adult age group. A preoperative diagnostic suspicion of cysticercosis is important in patients with cystic lesions because specific drug treatment is available. Treatment with anti-helmintics, particularly albendazole, should be considered in patients before surgery.

\section{REFERENSES:}

1. Baily GG: Cysticercosis. In Manson's Tropical Disease 21st edition. Edited by: Cook GC, Zumla A. London: Saunders; 2003:1584-1595.

2. Ash LR, Orihel TC. Atlas of human parasitology. Chicago: Amer Soc Clin Pathol 1984; 194.

3. Amatya BM, Kimula Y. Cysticercosis in Nepal. A histopathologic study of sixty-two cases. Amer J Surg Pathol 1999; 23: 1276-9.

4. Krishnaswami CS: Case of Cysticercus cellulose. Ind Med Gaz 1912, 27:43-44.

5. Wadia N, Desai S, Bhatt M: Disseminated cysticercosis. New observations, including CT scan findings and experience with treatment by praziquantel. Brain 1988, 111:597-614. 


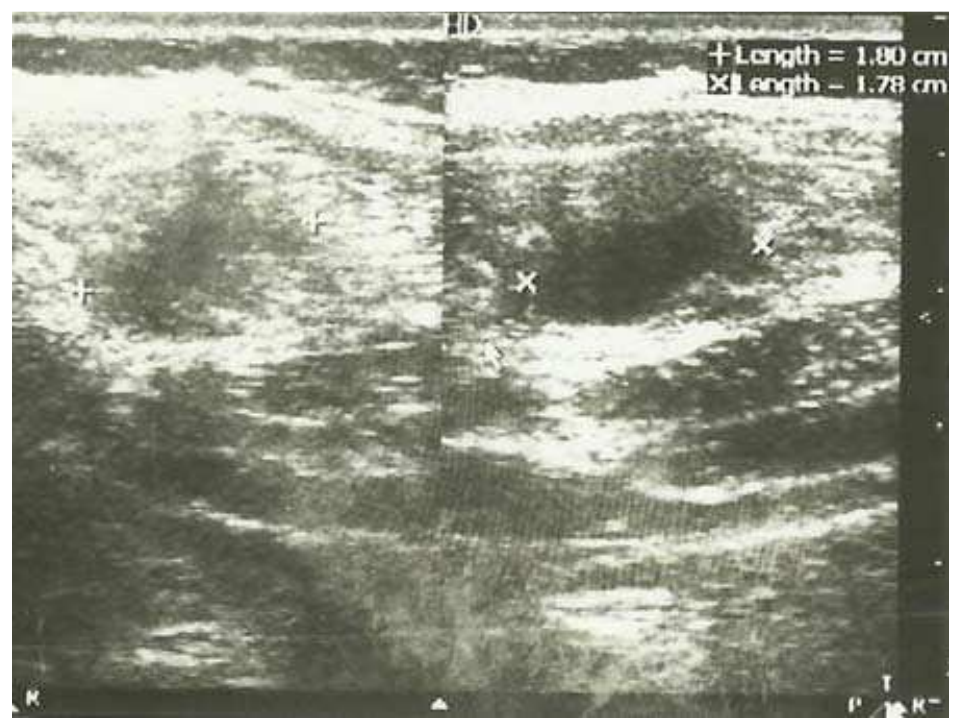

Fig:1 and 2, USG Abdomen, Right parietal wall showing Irregular heterogeneous partly cystic lesion deep to subcutaneous tissue and superficial/within external oblique aponeurosis.

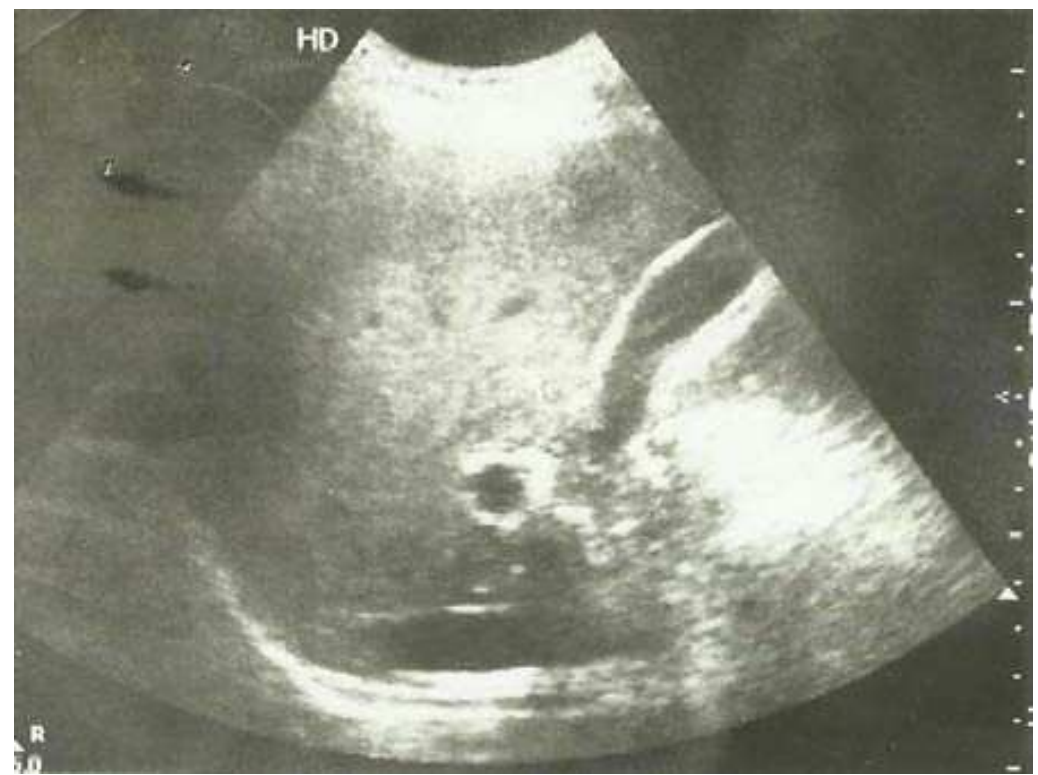

Fig- 2 


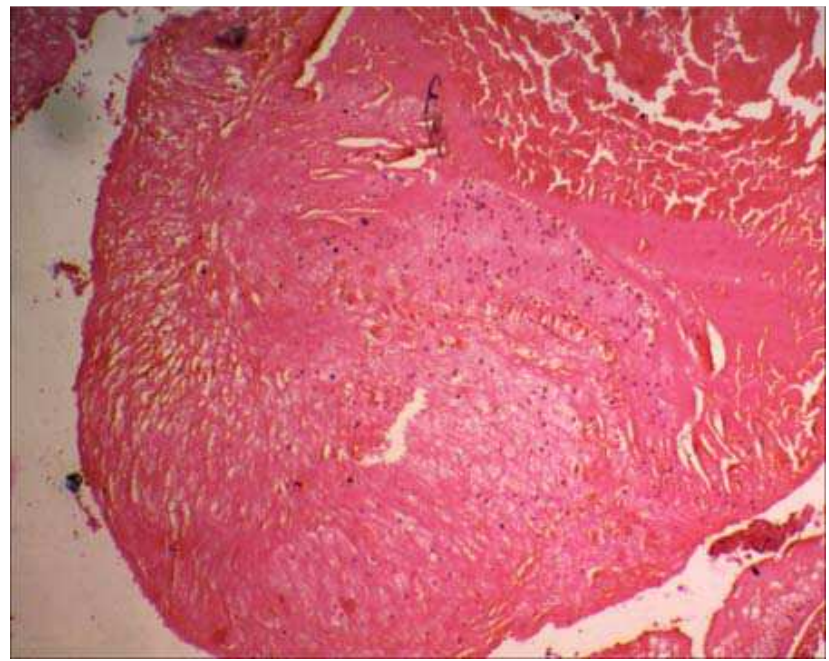

Fig:3- Cysticercosis cellulose, larval stage with degenerating sucker (H \& E stained section $\mathrm{x} 400$ )

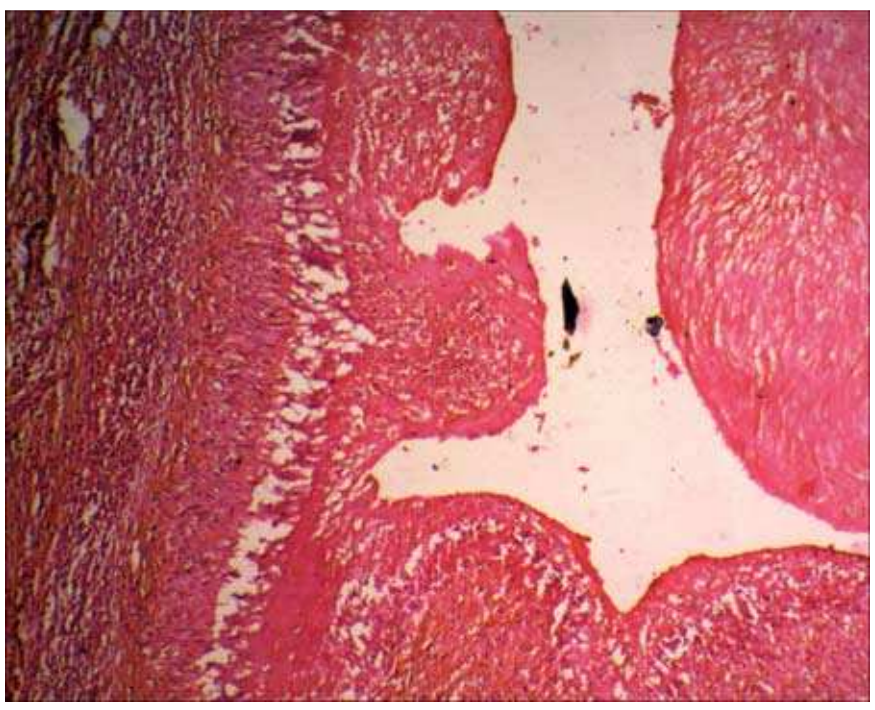

Fig:4, Cysticercosis cellulose, larval stage showing degenerating sucker with surrounding inflammatory reaction consisting of eosinophils, lymphocytes \& plasma cells -Arrow top panel at left ( $\mathrm{H} \& \mathrm{E}$ stained section $\mathrm{x} 400)$ 


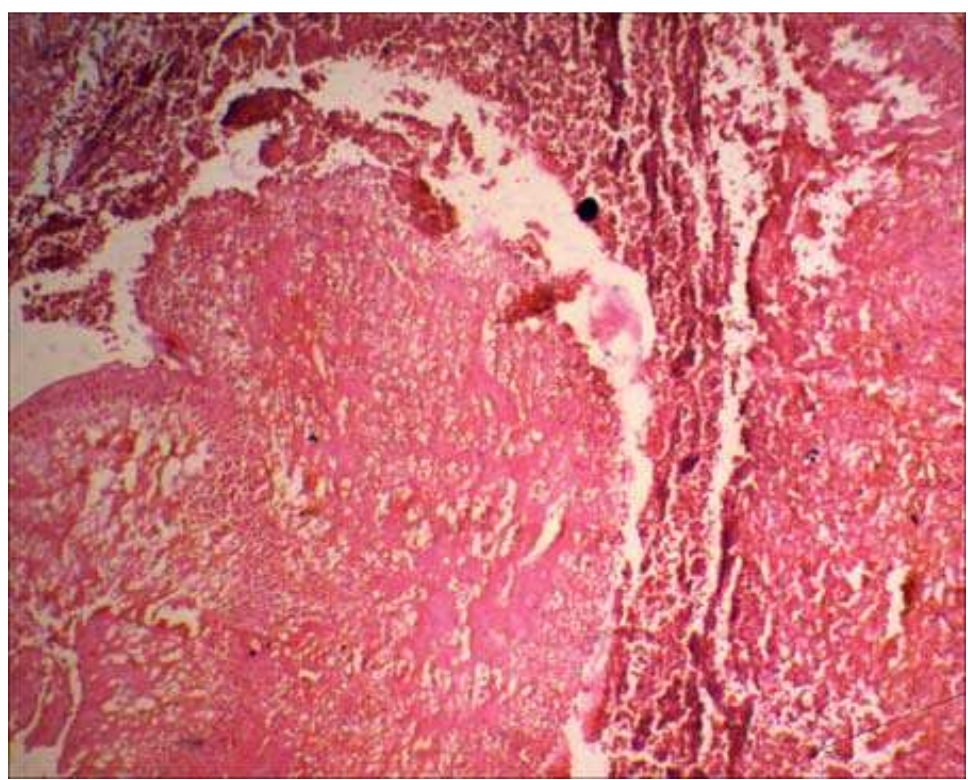

Fig:5 Cysticercosis cellulose, showing degenerating larva with surrounding intense inflammatory reaction with eosinophilic prominence, arrow bottom panel at right (H \& E stained section $\mathrm{x} 400$ )

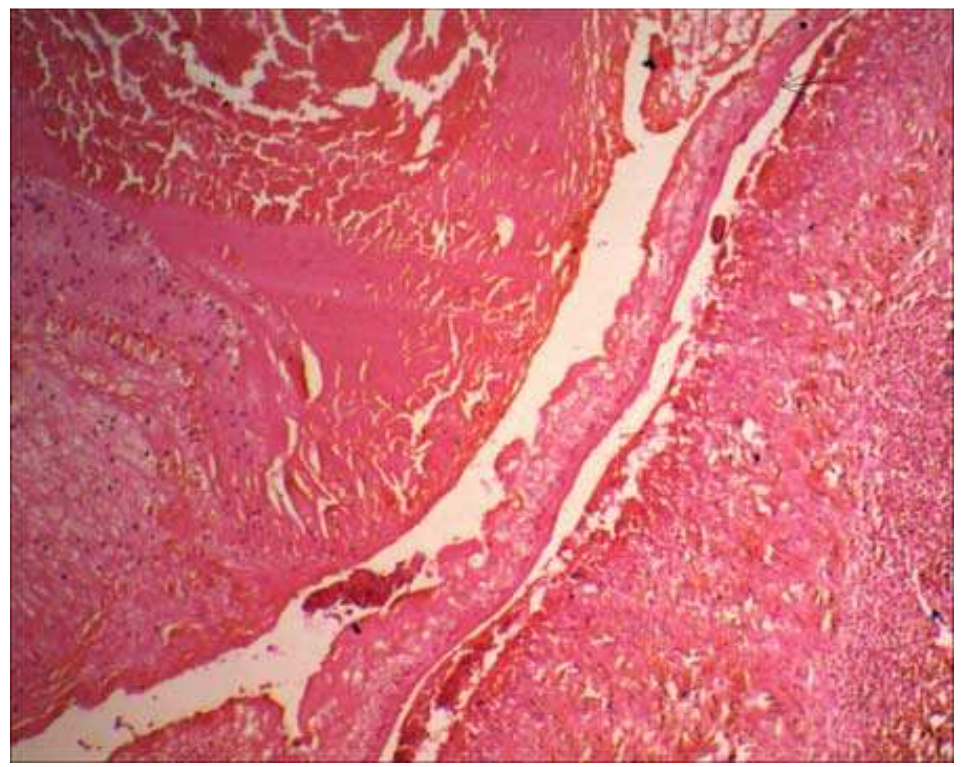

Fig: 6, Cysticercosis cellulose, larva with fragments of wall, arrow upper panel at right (H \& E stained section $\mathrm{x} 400$ ) 